\title{
КОДИФИКАЦИЯ ЗАКОНОДАТЕЛЬСТВА И ЕЕ ОСОБЕННОСТИ В СФЕРЕ ИНТЕЛЛЕКТУАЛЬНЫХ ПРАВ: ТЕОРЕТИКО-ПРАВОВЫЕ АСПЕКТЫ
}

Аннотация: Раскрываются концептуальные вопросы, связанные с кодификацией как правовым феноменом и особенностями ее реализации применительно к сфере регулирования интеллектуальных прав. Цель кодификации состоит в развитии и обновлении системы права в целом, исходя из потребностей современного общества. В сфере интеллектуальных прав такое обновление должно заключаться в переосмыслении места интеллектуальных прав в правовой системе, а также в новом взгляде на принциипы регулирования в ичелях обеспечения в условиях информационного общества баланса интересов всех взаимодействующих субъектов. Автор показывает, что помимо вопросов юридической техники (рационализации и систематизации законодательства) часть четвертая Гражданского кодекса решала также идеологические задачи. В статье освещены основные подходы к кодификации законодательства об интеллектуальной собственности в зарубежных странах. В процессе подготовки статьи применялись общенаучные (сравнение, анализ, синтез, абстрагирование, обобщение) и частнонаучные методы (формально-догматический, сравнительно-правового исследования и др.). Цивилистическая идеология проведенной кодификаиии препятствует формированию межотраслевых связей и оформлению института интеллектуальных прав как комплексного правового института. По мнению автора, искусственная консервация действующей системы регулирования посредством кодификации в долгосрочной перспективе способна принести не меньше вреда, чем необдуманные реформы, которым, как показывает практика, не может оказывать действенного сопротивления даже Гражданский кодекс. Abstract: This article expounds conceptual issues relating to the codification as a legal phenomenon and the specifics of its realization pertaining to the area or regulation of intellectual laws. The purpose of codification is the development and improvement of the legal system as a whole based on the demands of modern society. The article sheds light on the key approaches to the codification of laws on intellectual property within foreign nations. During the course of research, the author used general scientific (comparison, analysis, synthesis, abstraction, generalization) methods as well as private methods of observation (formal-dogmatic, legal comparative, and others). In author's opinion, an artificial conservation of a functioning system of regulation by codification, in a long run can cause just as much harm as careless reforms, to which even the Civil Code is unable to mount an effective opposition.

Ключевые слова: Кодификация, инкорпорация, межотраслевые связи, комплексный правовой институт, идеология, интеллектуальные права, система права, систематизация законодательства, информациионое общество, баланс интересов.

Keywords: Codification, incorporation, industrial connections, complex legal institution, ideology, intellectual laws, legal system, systematization of law, information society, balance of interests.

фера интеллектуальных прав характеризуется не только динамичностью своего развития, которая приводит к неопределенности и неустойчивости регулирования, но и несогласованностью научных комментариев, позиций и оценок. Одной из дискуссионных тем, которая имеет как концептуальное, так и теоретико-правовое значение, является вопрос о целесообразности и эффективности проведенной в 2006 году кодификации законодательных норм в сфере регулирования интеллектуальных прав.
Проект четвертой части Гражданского кодекса (Раздел VII Права на результаты интеллектуальной деятельности и средства индивидуализации) был подвергнут серьезной критике, как со стороны юристов-практиков, так и со стороны научного сообщества ${ }^{1}$. Доктор

\footnotetext{
${ }^{1}$ См.: Стенограмма обсуждения части 4 Гражданского кодекса в редакции газеты «Известия» (с участием А.Л. Маковского, Л.А. Трахтенгерц, М.А. Федотова, И.А. Зенина, А.Н. Козырева и др.). Документ доступен по электронному адресу: http://www.
} 
DOI: $10.7256 / 1811-9018.2014 .11 .13319$

При цитировании этой статьи сноска на dоі обязательна

\section{Право и политика $11(179) \cdot 2014$}

юридических наук А.П. Сергеев так охарактеризовал проведенную правовую реформу: «Очередная реформа российского законодательства об интеллектуальной собственности, связанная с принятием части четвертой $Г К$, по нашему глубокому убеждению, вряд ли серьезно улучшит охрану интеллектуальной собственности в нашей стране, но породит множество проблем, о которых вряд ли задумывались разработчики ее проекта и которые могут свести на нет все ее немногочисленные достижения» ${ }^{2}$. Доктор юридических наук, начальник Отдела права Евразийского патентного ведомства В.И. Еременко придерживается сходной позиции: «С включением в ГК РФ большого количества норм административного права кодификация по сути подменена инкорпорацией, когда сравнительно небольшое количество общих положений дополнено по существу механическим переносом специальных законов в сфере интеллектуальной собственности» ${ }^{3}$.

Для объективной оценки правомерности критических суждений относительно части четвертой Гражданского кодекса требуется, во-первых, правильное понимание сути и задач, которые решает любая кодификация, и, во-вторых, факторы, определяющие успех кодификации, и, наконец, в-третьих, анализ характерных особенностей и рисков кодификации в области, регулирующей наиболее динамичную область современной экономики - производство и распространение инновационных продуктов и технологий.

В отличие от инкорпорации кодификация подразумевает новое качество обобщения, благодаря которому выстраивается целостная система регулирования. Согласно точке зрения ведущего конституционалиста В.Д. Зорькина, конечная цель кодификации заключается не в совершенствовании отдельной отрасли или подотрасли законодательства, а развитие системы права в целом. В качестве критериев результативности кодификации ученый указывает собственно правовой,

copyright.ru/ru/library/analytika/obsuzhdenie_4_gk/; Постраничные замечания на проект четвертой части ГК РФ. // Приложение к Итоговому документу расширенного заседания Кафедры ЮНЕСКО по авторскому праву и другим правам интеллектуальной собственности от 17/03/2006; Городов, О. А. О проекте части четвертой Гражданского кодекса Российской Федерации. // Правоведение. 2006. № 6. С. 36 - 51.

2 Сергеев А.П. Основные проблемы правовой охраны интеллектуальной собственности в Российской Федерации на современном этапе. // Интеллектуальная собственность. Актуальные проблемы теории и практики. М., ЮРАЙТ, 2008. С.10.

${ }^{3}$ Еременко В.И. Введение. // Гаврилов Э.П., Еременко В.И. Комментарий к части четвертой Гражданского кодекса Российской Федерации (постатейный). М.: Экзамен, 2009. С.19. а именно доктринальное и юридико-техническое качество кодификации, и внеправовой - «содержательное соответствие кодифицируемых норм принципам права и потребностям развития общества в конкретноисторических условиях» ${ }^{4}$. Мы солидарны с позицией В.Д. Зорькина и хотели бы подчеркнуть несколько важных идей, которые содержатся в приведенных тезисах. Необходимо обратить особое внимание на то, что кодификация не ограничивается фиксацией законодательной статики и решает задачу развития законодательства в соответствии с новыми общественными потребностями. В сферах, где происходит обновление правовых институтов, а именно такой сферой является право интеллектуальной собственности, требуется переосмысление принципов регулирования. Применительно к сфере интеллектуальных прав такое переосмысление необходимо, прежде всего, в целях обеспечения в условиях информационного общества баланса интересов всех взаимодействующих субъектов.

Как представляется, состоявшаяся кодификация не в полной мере соответствует вышеприведенным критериям. В своей книге «Кодификации» известный французский юрист Р. Кабрияк подчеркивает, что помимо юридикотехнических целей, к которым ученый относит, в первую очередь, рационализацию, кодификация практически всегда преследует также социальные, политические или идеологические цели ${ }^{5}$. Последние, а именно идеологические цели, мы полагаем наиболее значимыми для нашего анализа. Часть четвертая Гражданского кодекса отражает цивилистическую идеологию. Характеризуя единую концепцию кодификации, доктор юридических наук, профессор А.Л. Маковский прямо указывает на то, что исключительное право «образует и почти исчерпывает ту отрасль гражданского права, которую принято называть «правом интеллектуальной собственности» ${ }^{6}$. По нашему мнению, отстаивая цивилистическую идеологию, разработчики оставили без внимания актуальный, как в научном, так и в практическом плане, вопрос о своеобразии и комплексном характере института интеллектуальных прав. Будучи учеными и профессионалами разработчики не могли не отразить при кодификации принципиальные отличия и особенности, связанные с регулированием интеллектуальных прав, что привело к реализации модели «кодекса в кодексе».

\footnotetext{
4 Зорькин В.Д. Право в условиях глобальных перемен. М. : Норма, 2013. C.76

${ }^{5}$ Кабрияк Р. Кодификации. М.: Статут, 2007. С.214-215, 262-265.

${ }^{6}$ Маковский А.Л. О кодификации гражданского права. М.: Статут.2010. С.590.
} 
Кодификация, однако, решала и более конкретные задачи - систематизации законодательства по охране интеллектуальной собственности и гармонизации с международными актами. На наш взгляд, при имеющихся недостатках части четвертой Гражданского кодекса, о чем свидетельствуют принятые в 2014 году комплексные поправки ${ }^{7}$, данные задачи были в большей или меньшей степени решены. В то же время, критические аргументы, которые высказывались в адрес кодификации - включение большого числа административных норм, недостатки понятийного аппарата, а также содержательные упущения - также отчасти справедливы. Их основная причина, как мы считаем, заключается в том, что Р. Кабрияк назвал «правовым пуантилизмом», т.е. попыткой отрегулировать абстрактными нормами все возможные конкретные ситуации ${ }^{8}$.

Обращаясь к зарубежному опыту, необходимо отметить, что принятие Францией Кодекса по интеллектуальной собственности, было осознанным решением. Самостоятельный характер интеллектуальных прав как сферы регулирования не ставился под сомнение и основной задачей, которую решала кодификация, была систематизация законодательства. В Голландии, действительно, обсуждалась идея о включении интеллектуальной собственности в гражданский кодекс, но в итоге была полностью отброшена. Другим примером может служить Германия. В 2011 году в Германии был опубликован Модельный закон по интеллектуальной собственности (Modellgesetz für geistiges Eigentum), авторы которого посчитали нецелесообразным опираться на российский опыт, хотя в качестве своего основного достижения рассматривают разработку общей части закона9.

Оценивая кодификацию с точки зрения глобальных тенденции в развитии регулирования интеллектуальных прав, необходимо акцентировать внимание на том, что, сохраняя гражданско-правовую основу, институт интеллектуальных прав приобретает все больше ха-

\footnotetext{
7 Поправки к части четвертой Гражданского кодекса, принятые в 2014 году, т.е. уже через шесть лет после состоявшейся кодификации (а подготовленные за два года до этого), являются достаточно масштабными, чтобы подтвердить правоту тех, кто предупреждал о рисах, связанных с необходимостью постоянной модернизации, нарушающей стабильность гражданского законодательства. См.: Федеральный закон от 12.03.2014 № 35Ф3 «О внесении изменений в части первую, вторую и четвертую Гражданского кодекса Российской Федерации и отдельные законодательные акты Российской Федерации».

${ }^{8}$ Кабрияк Р. Кодификации. М.: Стаут, 2007. С. 406-412.

${ }^{9}$ Ahrens H.-J., McGuireM.-R. Modellgesetz für Geistiges Eigentum. Normtext. München, 2011. S.49.
}

рактер межотраслевого института. Понимание права интеллектуальной собственности как сферы действия исключительно гражданского права представляет собой обеднение его содержания. Такой подход выносит за скобки, «замораживает» концептуальные вопросы, которые требуют не полемики и односложных ответов, а продуктивного диалога в профессиональном сообществе и всестороннего научного исследования. Избыток императивных правовых норм и, по сути, привилегированное положение правообладателя существенно затрудняют реализацию таких основополагающих принципов гражданского права, как принцип диспозитивности и принцип равенства участников гражданских правоотношений. Аналогичные характеристики потребительского и трудового права обусловили их выделение в самостоятельные отрасли права, однако в отношении права интеллектуальной собственности обозначенная проблема практически не обсуждается. Это не означает, что применение гражданско-правовых механизмов в регулировании интеллектуальных прав отходит на второй план. Напротив, можно говорить о «цементирующей» роли гражданского права и о тенденции к расширению использования гражданскоправовых конструкций. Однако данный факт не должен служить основанием для сужения дискуссионного поля и тем более для отказа от исследования межотраслевых противоречий и реально существующего конфликта интересов (противостояния старых и новых бизнесмоделей, конфликта между интересами общества и имущественными интересами правообладателей).

С учетом вышесказанного, кодификацию законодательства об интеллектуальной собственности в рамках Гражданского кодекса следует рассматривать как искусственное препятствие для межотраслевого взаимодействия и формирования взвешенных законодательных и доктринальных позиций по вопросам, касающимся межотраслевых связей. Существующие межотраслевые проблемы (соотношение регулирования интеллектуальных прав с антимонопольным регулированием, защитой персональных данных, защитой прав потребителей и др.) не могут быть решены исключительно средствами гражданского права, а их замалчивание только усложняет задачу нахождения баланса интересов всех участников правоотношений в сфере интеллектуальных прав. Конечно, можно согласиться с тем, что локализация интеллектуальных прав в Гражданском кодексе естественным образом снижает «политизированность» права интеллектуальной собственности как общую негативную тенденцию его развития в современном информационном обще- 
DOI: 10.7256/1811-9018.2014.11.13319

При цитировании этой статьи сноска на доі обязательна

\section{Право и политика $11(179) \cdot 2014$}

стве. Так, профессор частного права Стокгольмского университета, директор Института интеллектуальной собственности Мариан Левин (Marianne Levin) отмечает возрастающее политическое, экономическое и общественное давление, все больше детерминирующее правовую политику и не позволяющее принимать взвешенных решений. Вывод ученого заключается в том, что «чем дольше такая политизация будет продолжаться, тем меньше ценности, ради соблюдения которых были созданы права интеллектуальной собственности, будут соблюдаться и тем меньше права интеллектуальной собственности будут соответствовать своим целях, будь то вознаграждение, вдохновение или стимулирование роста ${ }^{10}$. По нашему мнению, однако, искусственная консервация действующей системы регулирования посредством кодификации в долгосрочной перспективе способна принести не меньше вреда, чем необдуманные реформы, которым, как показывает практика, не может оказывать действенного сопротивления даже Гражданский кодекс ${ }^{11}$.

\section{Библиография:}

1. Городов, О. А. О проекте части четвертой Гражданского кодекса Российской Федерации. //Правоведение. 2006. № 6. С. $36-51$.

2. Еременко В.И. Введение. // Гаврилов Э.П., Еременко В.И. Комментарий к части четвертой Гражданского кодекса Российской Федерации (постатейный). М.: Экзамен, 2009. С. 18-22.

3. Зорькин В.Д. Право в условиях глобальных перемен: монография / В. Д. Зорькин. - М.: Норма, 2013. - 496 с.

4. Кабрияк, Р. Кодификации /Р. Кабрияк; Пер. и авт. вступ. ст. Л. В. Головко. - М.: Стаут, 2007. - 476 с.

5. Маковский А.Л. О кодификации гражданского права. - М.: Статут. 2010. - 736 с.

6. Сергеев А.П. Основные проблемы правовой охраны интеллектуальной собственности в Российской Федерации на современном этапе. // Интеллектуальная собственность. Актуальные проблемы теории и практики. М., ЮРАЙТ, 2008. С.10-17.

7. Ahrens H. - J., McGuireM. - R. Modellgesetz für Geistiges Eigentum. Normtext. München, 2011. - 432 S.

8. Levin M. The Need for Climate Improvement in Intellectual Property Law. // Patents and Technological Progress in a Globalized World. Springer-Verlag Berlin Heidelberg, 2009. P.811-828.

\section{References (transliterated):}

1. Gorodov, O. A. O proekte chasti chetvertoi Grazhdanskogo kodeksa Rossiiskoi Federatsii. //Pravovedenie. 2006. № 6. S. 36 -51.

2. Eremenko V.I. Vvedenie. // Gavrilov E.P., Eremenko V.I. Kommentarii k chasti chetvertoi Grazhdanskogo kodeksa Rossiiskoi Federatsii (postateinyi). M.: Ekzamen, 2009. S.18-22.

3. Zor'kin V.D. Pravo v usloviyakh global'nykh peremen : monografiya / V. D. Zor'kin. - M.: Norma, 2013. - $496 \mathrm{~s}$.

4. Kabriyak, R. Kodifikatsii /R. Kabriyak ; Per. i avt. vstup. st. L. V. Golovko. - M.: Staut, 2007. -476 s.

5. Makovskii A.L. O kodifikatsii grazhdanskogo prava. - M.: Statut. 2010. $-736 \mathrm{~s}$.

6. Sergeev A.P. Osnovnye problemy pravovoi okhrany intellektual'noi sobstvennosti v Rossiiskoi Federatsii na sovremennom etape. // Intellektual'naya sobstvennost'. Aktual'nye problemy teorii i praktiki. M., YuRAIT, 2008. S.10-17.

7. Ahrens H. - J., McGuireM. - R. Modellgesetz für Geistiges Eigentum. Normtext. München, 2011. - 432 S.

8. Levin M. The Need for Climate Improvement in Intellectual Property Law. // Patents and Technological Progress in a Globalized World. Springer-Verlag Berlin Heidelberg, 2009. P.811-828. 